\title{
Age-Dependent Cerebrovascular Abnormalities and Blood Flow Disturbances in APP23 Mice Modeling Alzheimer's Disease
}

\author{
Nicolau Beckmann, ${ }^{1}$ Alexandra Schuler, ${ }^{3}$ Thomas Mueggler, ${ }^{1}$ Eric P. Meyer, ${ }^{3}$ Karl-Heinz Wiederhold, ${ }^{2}$ \\ Matthias Staufenbiel, ${ }^{2}$ and Thomas Krucker ${ }^{4}$ \\ ${ }^{1}$ Discovery Technologies Center and ${ }^{2}$ Nervous System Department, Novartis Institutes for BioMedical Research, CH-4002 Basel, Switzerland, ${ }^{3}$ Department \\ of Zoology, University of Zurich, CH-8002 Zurich, Switzerland, and ${ }^{4}$ Department of Neuropharmacology, The Scripps Research Institute, La Jolla, California \\ 92037
}

Neuropathological changes associated with Alzheimer's disease (AD) such as amyloid plaques, cerebral amyloid angiopathy, and related pathologies are reproduced in APP23 transgenic mice overexpressing amyloid precursor protein (APP) with the Swedish mutation. Magnetic resonance angiography (MRA) was applied to probe, in vivo, the cerebral arterial hemodynamics of these mice. Flow voids were detected at the internal carotid artery of 11-month-old APP23 mice. At the age of 20 months, additional flow disturbances were observed in large arteries at the circle of Willis. Vascular corrosion casts obtained from the same mice revealed that vessel elimination, deformation, or both had taken place at the sites where flow voids were detected by MRA. The detailed three-dimensional architecture of the vasculature visible in the casts assisted the identification of smaller vessels most likely formed as substitution or anastomosis within the circle of Willis. Angiograms and corrosion casts from nontransgenic, age-matched mice manifested no major abnormalities in the cerebrovascular arterial flow pattern. Because no transgene overexpression has been found in the cerebrovasculature of APP23 mice and no deposits of amyloid- $\beta(\mathrm{A} \beta)$ were observed in large arteries in the region of the circle of Willis, the present results suggest that soluble $A \beta$ may exert deleterious effects on the vasculature. Our findings support the idea that cerebral circulatory abnormalities evolving progressively could contribute to $\mathrm{AD}$ pathogenesis. The study also shows the power of MRA to identify changes of vascular function in genetically engineered mice. MRA as a noninvasive technique could be applied to test new therapeutic concepts in animal models of AD and in humans.

Key words: Alzheimer's disease; amyloid precursor protein (APP); angiography; angiopathy; cerebral amyloid angiopathy (CAA); circle of Willis; magnetic resonance angiography (MRA); magnetic resonance imaging (MRI); soluble amyloid; transgenic mice; vascular corrosion cast

\section{Introduction}

The pathology of Alzheimer's disease (AD) is characterized by amyloid- $\beta(\mathrm{A} \beta)$ peptide-containing plaques, neurofibrillary tangles consisting of aggregated, hyperphosphorylated tau, extensive neuritic degeneration, and distinct neuron loss. The typical clinical picture of $\mathrm{AD}$ includes a progressive decline of memory function, often accompanied by other clinical signs such as agitation, aggression, sleep disturbances, and social withdrawal. Vascular abnormalities coexist commonly with the histological features of AD (Snowdon et al., 1997; Sparks, 1997; Grammas, 2000). Deposition of $\mathrm{A} \beta$ peptide in cerebral vessel walls, known as cerebral amyloid angiopathy (CAA), is very frequent, but its contribution

Received May 12, 2003; revised July 28, 2003; accepted July 28, 2003.

T.K. was supported by the Novartis Research Foundation, and A.S. and E.P.M. were supported by the Swiss National Science Foundation. We thank Dr. Markus Rudin for critically reading this manuscript.

Correspondence should be addressed to Dr. Nicolau Beckmann, Discovery Technologies Center, Novartis Institutes for BioMedical Research, Lichtstrasse 35, WSJ-386.2.09, CH-4002 Basel, Switzerland. E-mail: nicolau.beckmann@pharma.novartis.com.

T. Mueggler's present address: Division of Neurophysiology, National Institute for Medical Research, Mill Hill, London NW7 1AA, UK.

Copyright $\odot 2003$ Society for Neuroscience $\quad$ 0270-6474/03/238453-07\$15.00/0 to the onset of dementia is unknown (De la Torre and Mussivand, 1993). In fact, hemorrhages correlating with CAA and AD often occur in vessels not affected by amyloid deposition (Gilbert and Vinters, 1983).

Transgenic mice play a fundamental role in the study of $\mathrm{AD}$ mechanisms (for review, see Bornemann and Staufenbiel, 2000; Andersen, 2001; Duff and Rao, 2001; Hock and Lamb, 2001) and are used to test novel therapies. APP23 mice contain a human amyloid precursor protein $\left(\mathrm{APP}_{751}\right)$ cDNA with the Swedish double mutation at position 670/671 under the control of the neuron-specific Thy-1 promoter. These animals express APP in sevenfold excess compared with the endogenous murine APP. Although the transgenic APP expression is turned on during the first month after birth, $A \beta$ deposition starts at $\sim 6$ months of age in female mice (and 1-2 months later in male mice) in the frontal cortex and in the subiculum. The deposits increase in number and size thereafter and finally occupy substantial portions of the neocortex, hippocampus, and thalamus (Sturchler-Pierrat et al., 1997). Although the APP transgene is only expressed in neurons, in addition to amyloid plaques, the mouse model develops substantial cerebrovascular accumulation of $\mathrm{A} \beta$ easily detectable at 
the age of $\sim 12$ months (Calhoun et al., 1999; Bornemann and Staufenbiel, 2000; Sturchler-Pierrat and Staufenbiel, 2000). CAA and associated pathologies such as alterations in the vascular integrity and microhemorrhages (Winkler et al., 2001) exhibit similarities to what is observed in aged individuals and AD patients (Probst et al., 1991; Staufenbiel and Sommer, 1998).

Recently, high-resolution magnetic resonance angiography (MRA) has been introduced as a means to investigate the arterial cerebrovascular hemodynamics noninvasively in rats (Reese et al., 1999) and mice (Beckmann et al., 1999; Beckmann, 2000). In the work reported here, the technique was used to probe the cerebral arterial hemodynamics of APP 23 transgenic mice in vivo. Angiograms were compared with vascular corrosion casts (Meyer, 1989; Meyer et al., 2000) to identify the underlying structural changes.

\section{Materials and Methods}

Experiments were performed according to Swiss federal regulations for animal protection and were approved by the Veterinary Authority of Basel.

Animals. Ten-month-old male C57Bl/6 mice (Iffa Credo, St. Aulbinles-Elbeuf, France) served as an independent control group $(n=8)$.

The generation of APP23 mice containing the murine Thy- 1 promoter driving neuron-specific expression of human mutated $\mathrm{APP}_{751}$ was described in detail by Sturchler-Pierrat et al. (1997). MRA and cast studies were performed on male APP23 mice and controls from the same or parallel litters at ages of $6.8 \pm 1$ (6.5 \pm 1 for controls), $11.3 \pm 1$ (11.4 \pm 1 for controls), and $20.1 \pm 1$ (20.2 \pm 1 for controls) months. Ten animals were examined in each group at the different ages. Male APP23 mice at 7 months of age contain only a few isolated amyloid plaques. The plaque load (expressed as a percentage of neocortical area) is in the range of $0.3 \%$ at 12 months to $9 \%$ at 22 months of age.

Histological analysis was performed on another cohort of 12-, 14-, and 22-month-old APP23 mice, with 10 animals in each age group.

MRA. For the MRA investigations, animals were anesthetized with $1.3 \%$ isoflurane (Abbott, Cham, Switzerland) in a mixture of oxygen and $\mathrm{N}_{2} \mathrm{O}(1: 2)$ administered via a face mask. The body temperature of the mice was kept at $37^{\circ} \mathrm{C}$. No stereotactic holding was used.

Measurements were performed with a Biospec 47/40 spectrometer (Bruker, Karlsruhe, Germany) operating at 4.7 T, equipped with an actively shielded gradient system. The operational software of the scanner was Paravision (Bruker). Time-of-flight (TOF) angiograms were obtained using a three-dimensional (3D) gradient-echo sequence with the following imaging parameters: repetition time, $40 \mathrm{msec}$; echo time, 1.6 msec; matrix, $96 \times 192 \times 64$; field-of-view, $1.44 \times 1.92 \times 0.64 \mathrm{~cm}^{3}$; and two averages. Total acquisition time for an angiogram was $16.4 \mathrm{~min}$. The radio frequency pulse was frequency-selective, thereby exciting a coronal slice $0.64 \mathrm{~cm}$ thick. The excitation pulse was $\sim 20^{\circ}$. Magnetization transfer contrast was attained by a frequency-selective Gaussian pulse of 3500 $\mu$ sec duration, with $2 \mu \mathrm{T}$ strength and a frequency offset of $2500 \mathrm{~Hz}$ with respect to the water resonance, preceding the $3 \mathrm{D}$ gradient-echo sequence by $2.4 \mathrm{msec}$. An Alderman-Grant-type resonator of $2 \mathrm{~cm}$ diameter was used for excitation and detection. The pixel size of the raw data was $150 \times$ $100 \times 100 \mu^{3}$. All data were zero-filled to $(256)^{3}$ for reconstruction. Angiograms were obtained by generating maximum-intensity projections (MIPs) using standard software from the magnetic resonance (MR) system after zero-filling the raw data. The MRA acquisition parameters had been optimized previously (Beckmann et al., 1999; Beckmann, 2000) in normal wild-type mice of different strains matching in weight to the animals participating in this study.

Vascular corrosion cast. Mice were deeply anesthetized with pentobarbital ( $100 \mathrm{mg} / \mathrm{kg}$, i.p.) and perfused through the left ventricle of the heart. The left ventricle was punctured with a 19 gauge needle from a winged infusion set (SV-19BLK; Termudo, Elkton, MD), which was connected to an airtight pressurized syringe containing the rinsing solution (Ringer's solution with $250,000 \mathrm{U} / \mathrm{l}$ heparin at $35^{\circ} \mathrm{C}$ ). The right atrium was punctured to provide outflow, and the perfusate was injected under a

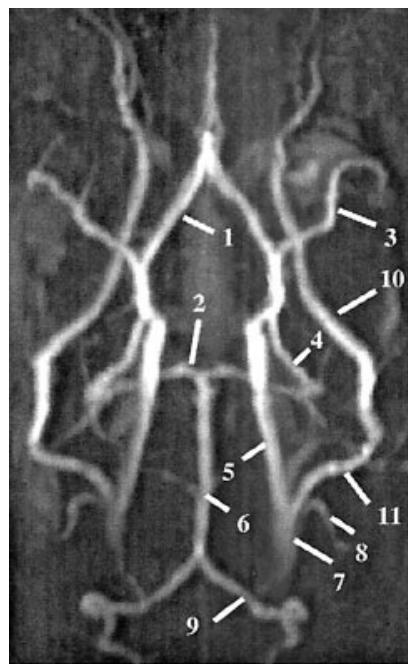

1) anterior cerebral artery; 2) superior cerebellar artery; 3) middle cerebral artery; 4) posterior cerebral artery; 5) internal carotid artery; 6) basilar artery; 7) common carotid artery; 8) external carotid artery; 9) vertebral artery; 10) palatine and 11) pterygo portion of pterygopalatine artery

Figure 1. Angiogram from a normal 10-month-old C57BI/6 mouse. The circle of Willis (1, 2 4) and small vessels emerging from it are well delineated.

pressure of $\sim 80-100 \mathrm{mmHg}$. The perfusion was continued for $2-5 \mathrm{~min}$ at a constant rate $(20-30 \mathrm{ml})$ followed by a prefixation solution $\left(35^{\circ} \mathrm{C}, 20\right.$ $\mathrm{ml}, 4 \%$ performaldehyde in PBS). Immediately afterward, $10 \mathrm{ml}$ of resin (Mercox/methyl-methacrylate; Ladd Research, Burlington, VT) was infused at the same rate. The resin-filled tissue was kept at room temperature overnight to complete resin curing. Soft tissue was removed from the head by maceration in $20 \% \mathrm{KOH}$ during $24 \mathrm{hr}$ at $50^{\circ} \mathrm{C}$, followed by decalcification in $5 \%$ formic acid $(12 \mathrm{hr})$. The casts were then thoroughly cleaned with and stored in distilled water before drying by lyophilization. Mounted on stubs, the casts were sputter-coated with gold-palladium for routine scanning electron microscopy. To quantify microvascular changes, photomicrographs were scanned, and the imaging software Image-Pro Plus (Media Cybernetics, Inc., Des Moines, IA) was used to measure diameters of capillaries between ramifications. Photo Paint (Corel Corp., Ottawa, Ontario, Canada) was used for photo montage.

Histology and immunohistochemistry. Histological analyses were performed according to procedures described by Sturchler-Pierrat et al. (1997) on brains from 12-, 14-, and 22-month-old APP23 mice. Brains from 10 animals in each age group were examined at different anatomical levels.

\section{Results}

The arterial cerebrovascular structure of living mice can be depicted by TOF MRA, which is sensitive to fast-flowing blood. Figure 1 shows a representative coronal MIP image from an angiogram of the head of a C57Bl/6 mouse. The circle of Willis as well as the middle and posterior cerebral arteries are well delineated, whereas venous structures are almost completely suppressed because of the low flow velocity.

A representative angiogram from 6-month-old APP23 transgenic mice is presented in Figure $2 a$. No major flow abnormalities were detected in the arterial cerebrovascular architecture at this age. Only minor flow voids were detected at the level of the pterygopalatine arteries outside the brain (in 5 of 10 mice; Table 1). Except for this change, angiograms from 6-month-old APP23 mice (Fig. 2a) were very similar to those obtained for control C57Bl/6 mice (Fig. 1). Angiograms from age-matched wild-type littermates were devoid of flow disturbances (data not shown). Corrosion casts from the brains of mice $<10$ months also showed no major abnormalities in the large cerebral arteries. A representative cast from a young APP23 mouse is displayed in Figure $2 b$.

At the age of 11 months, flow disturbances were present at the level of the carotid arteries in 7 of 10 APP23 mice (Fig. 3, Table 1). 

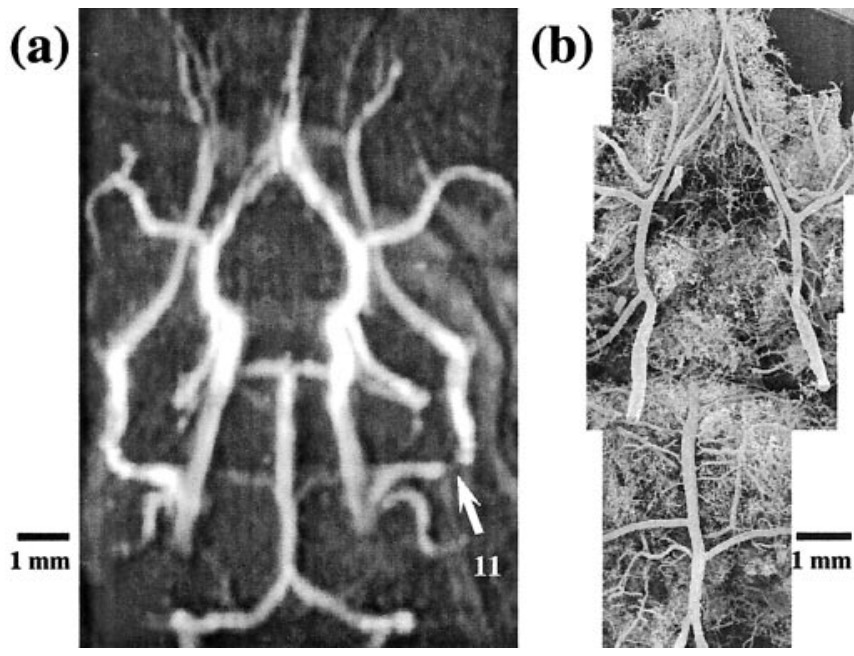

Figure 2. a, Angiogram from a 6-month-old APP23 mouse. No flow disturbances were detected by MRA in the cerebrovascular architecture of transgenic mice at this age. Minor flow voids were seen only at the level of the pterygopalatine arteries (11). $b$, Corrosion cast from the brain of a 7.5-month-old APP23 mouse. An intact circle of Willis is shown.

Flow voids were also detected in arteries outside the brain, at the level of the pterygopalatine, and in the external and common carotid arteries. No significant flow disturbances were seen in age-matched control littermates.

The angiogram of a 20-month-old littermate mouse (Fig. 4a) was comparable with that of a $\mathrm{C} 57 \mathrm{Bl} / 6$ control mouse (Fig. 1) except for flow voids appearing at the level of the pterygopalatine and the internal carotid artery (comparable in extent with APP23 transgenic mice of age 11 months; Fig. $2 b$ ). The intact flow pattern in the circle of Willis was confirmed by cast analysis of the cerebrovascular architecture of the same animal (Fig. $4 b$ ). Angiograms from six other 20-month-old littermate mice showed minor flow voids at the level of the pterygopalatine only, whereas the remaining three animals in this group had intact angiograms (Table 1).

In contrast, angiograms from 6 of 10 APP23 mice at 20 months of age presented significant flow voids in the main arteries of the circle of Willis. In addition to flow disturbances at the level of the pterygopalatine and the carotid arteries, large flow voids were seen in the anterior and posterior cerebral arteries and the middle cerebral arteries (Fig. 5a). Corrosion cast technology helped interpret the flow disturbances occurring in the angiograms. Vessel elimination and substitution (or rearrangement) occurred at the level of the posterior cerebral arteries (Fig. 5b),

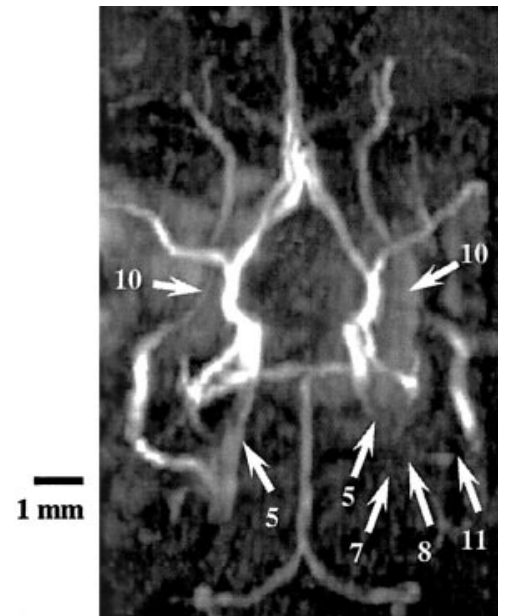

Figure 3. Angiogram from an 11-month-old APP 23 mouse. The arrows indicate flow disturbances at the level of the internal carotid arteries (5). Flow disturbances were also detected outside the brain, at the common (7) and external (8) carotid arteries and the pterygopalatine $(10,11)$.

where a significant flow void had been detected by MRA (Fig. 5a). Instead of a well developed posterior cerebral artery, multiple small vessels were present at this level on the left side of the circle of Willis (Fig. $5 b$, inset, compare with the right side and Fig. 1). Closer analysis of the angiogram reveals remaining flow through these tiny vessels (Fig. 5a). Also, the absent internal carotid artery on the left side of the angiogram was detected as vessel elimination by cast analysis. Interesting was the presence of a small artery connecting the left and right sides of the circle of Willis (Fig. 5a,b, \#). This vessel, which appeared faintly in the angiogram and could have been easily overlooked, probably maintained a diminutive flow around the circle of Willis in face of the vessel substitution at the level of the posterior cerebral arteries. Turbulence resulting from constriction of vessels could have been another cause of flow perturbation. Narrowing was present in the right middle cerebral artery (Fig. $5 c$ ), internal carotid artery (Fig. $5 d$ ), and posterior cerebral artery (Fig. $5 e$, left). Also, an inclusion of yet undetermined origin was detected at the level of the posterior cerebral artery (Fig. 5e, right). A summary of observed changes is shown in Table 1.

As already indicated in Figure 5, an asymmetric flow pattern at the level of the circle of Willis and also outside the brain was systematically observed in 20-month-old APP23 mice. Figure $6 a$ exemplifies this for the middle cerebral artery and, in addition, for the pterygopalatine, where a large flow void on the right side

Table 1. Summary of the vascular alterations observed in APP23 and littermate mice using MRA and corrosion casts

\begin{tabular}{|c|c|c|c|c|c|c|c|c|c|}
\hline \multirow[b]{2}{*}{ Artery } & \multirow[b]{2}{*}{ Location } & \multirow[b]{2}{*}{ MRA } & \multirow[b]{2}{*}{ Cast } & \multicolumn{3}{|l|}{ APP23 } & \multicolumn{3}{|l|}{ Wild-type } \\
\hline & & & & $6-7$ months & 11 months & 20 months & 7 months & 11 months & 20 months \\
\hline 1. Anterior cerebral & Brain & Flow voids & Narrowing, elimination & & & $6 / 10$ & & & \\
\hline 2. Superior cerebellar & Brain & & & & & & & & \\
\hline 3. Middle cerebral & Brain & Flow voids & Narrowing & & & $6 / 10$ & & & \\
\hline 4. Posterior cerebral & Brain & Flow voids & Narrowing, elimination & & & $6 / 10$ & & & \\
\hline 5. Internal carotid & Brain & Flow voids, elimination & Narrowing, elimination & & $7 / 10$ & $8 / 10$ & & & $1 / 10$ \\
\hline 6. Basilar & Brain & & & & & & & & \\
\hline 7. Common carotid & Periphery & Flow voids & Not analyzed & & $7 / 10$ & $8 / 10$ & & & \\
\hline 8. External carotid & Periphery & Flow voids & Not analyzed & & $7 / 10$ & $8 / 10$ & & & \\
\hline 9. Vertebral & Periphery & & Not analyzed & & & & & & \\
\hline 10. Palatine & Periphery & Flow voids & Not analyzed & $5 / 10$ & $8 / 10$ & $10 / 10$ & & & $7 / 10$ \\
\hline 11. Pterygopalatine & Periphery & Flow voids & Not analyzed & $5 / 10$ & $8 / 10$ & $10 / 10$ & & & $7 / 10$ \\
\hline
\end{tabular}

Ten animals were analyzed at each age. The numbers express how many animals showed alterations at a given artery. 
seemed to be compensated by an abnormally elevated flow on the corresponding contralateral artery. Cast analysis showed differences in diameters of the middle cerebral arteries of this animal (Fig. 6b).

Histology performed on an additional cohort of 22-month-old APP23 mice revealed deposition of amyloid in large leptomeningeal and neocortical arteries. However, no significant amyloid deposition was found in veins and in large arteries in the region of the circle of Willis.

\section{Discussion}

In this study we show evidence of agedependent alterations of cerebral blood flow and vascular architecture in APP23 transgenic mice using MRA and corrosion casts.

\section{Age-related blood flow disturbances attributable to cerebrovascular abnormalities in APP23 mice}

Angiograms from 6-month-old APP23 mice showed normal, undisturbed arterial cerebrovascular blood flow, similar to that of young nontransgenic animals (Beckmann et al., 1999; Beckmann, 2000). Localized flow voids at the level of the internal carotid arteries were apparent in APP23 mice at the age of 11 months. In 20-month-old mice, in addition to the carotids, substantial flow perturbations also affected other main arteries from the circle of Willis, the middle cerebral and the posterior cerebral arteries. Analysis of corrosion casts demonstrated that vessel elimination and substitution occurred at regions of the arterial cerebrovascular architecture where substantial flow voids had been detected by MRA. They also confirmed a loss of vessels in the circle of Willis. In contrast, angiograms and corrosion casts from nontransgenic mice manifested no major abnormalities in the cerebrovascular arterial flow pattern at any age.

A number of inseparably and dynamically interrelated factors, such as flow velocity, microturbulent flow, viscosity of blood, shear stress caused by the vascular wall, and vascular resistance, govern the dynamics of blood flow in cerebral vessels (De la Torre and Mussivand, 1993). Microturbulent flow, which disturbs the regular passage of blood, can develop when the usual shape of the vascular lumen becomes irregular, for example, locally thickened (as for fibrotic arteries), partially obstructed (atherosclerosis), or compressed. In this case, the flow pattern may become disrupted, and random swirls can build up, compromising the slow flow of the cell-free layer near the vessel wall. Thus, localized flow voids in the angiograms do not necessarily mean absence of flow but may be the consequence of microturbulence.

To help interpret the MRA data and to identify structural alterations underlying the dynamic MRA observations, we performed corrosion cast analysis. This method is unique because the three-dimensional organization of the vasculature is retained, including the dense network of the capillaries. Not only did casts confirm the MRA data, in addition, this method also helped devise possible explanations for the flow irregularities in the form of focal constriction of arteries, vessel elimination and rearrangement (see below), or the presence of inclusions. Although casting procedures have technical limitations, in the present situation, this technique is superior to standard histology because the threedimensional organization is retained.

\section{Vessel rearrangement}

In old APP23 mice, analysis of casts showed that vessel rearrangement and substitution occurred in the circle of Willis at locations where elimination of parts of arteries had taken place (Fig. 5), indicating that angiogenesis had occurred at these sites. These observations are consistent with intrathecal production of transforming growth factor $\beta$, a cytokine exerting both antiinflammatory and angiogenic properties, as well as promoting amyloidogenesis, observed in AD patients (Tarkowski et al., 2002) and in APP23 mice older than 12 months (S. Wiesli and M. Staufenbiel, unpublished results).

\section{Cerebrovascular abnormalities in transgenic models of $\mathrm{AD}$ and in patients}

Significant amounts of neuron-derived cerebrovascular amyloid have been reported in APP23 mice (Calhoun et al., 1999; Burgermeister et al., 2000; Winkler et al., 2001), leading to vascular damage. The frequency and severity of CAA in these animals are age-related. In 8-month-old APP23 mice, cerebrovascular amyloid is generally absent except for rare focal deposits in leptomeningeal vessels. In animals of $>19$ months, cerebrovascular amyloid deposits are encountered consistently throughout the neocortex, hippocampus, and thalamus. Leptomeningeal vessels are always heavily affected at this age (Winkler et al., 2001), a fact that was confirmed here by histological analysis.

Whereas deposition of amyloid in large arteries was seen only in leptomeningeal and neocortical arteries, MRA detected flow voids at the middle cerebral artery and at the level of the circle of Willis in old APP23 mice. These results indicate that vascular changes can be observed even when the amount of amyloid deposition on the vessels is negligible. Although fibril formation of $\mathrm{A} \beta$, leading to neurodegeneration and death, has constituted an important paradigm in AD research (Hardy and Higgins, 1992), soluble $\mathrm{A} \beta$ peptides display free radical-mediated vasoactive properties (Thomas et al., 1996) and have been shown recently to elicit vasoconstriction of vessels as large as the human middle cerebral and basilar arteries (Townsend et al., 2002). Circulating $\mathrm{A} \beta$ (1-40) can exert vasopressor actions in vivo (Arendash et al., 1999; Niwa et al., 2001), suggesting a pathophysiologic role for soluble $\mathrm{A} \beta$ in $\mathrm{AD}$ that precedes $\mathrm{A} \beta$ deposition and dementia onset. Moreover, Price et al. (1997) showed that the A $\beta$ peptide produces dysfunction in cerebral vessels, including large arteries 


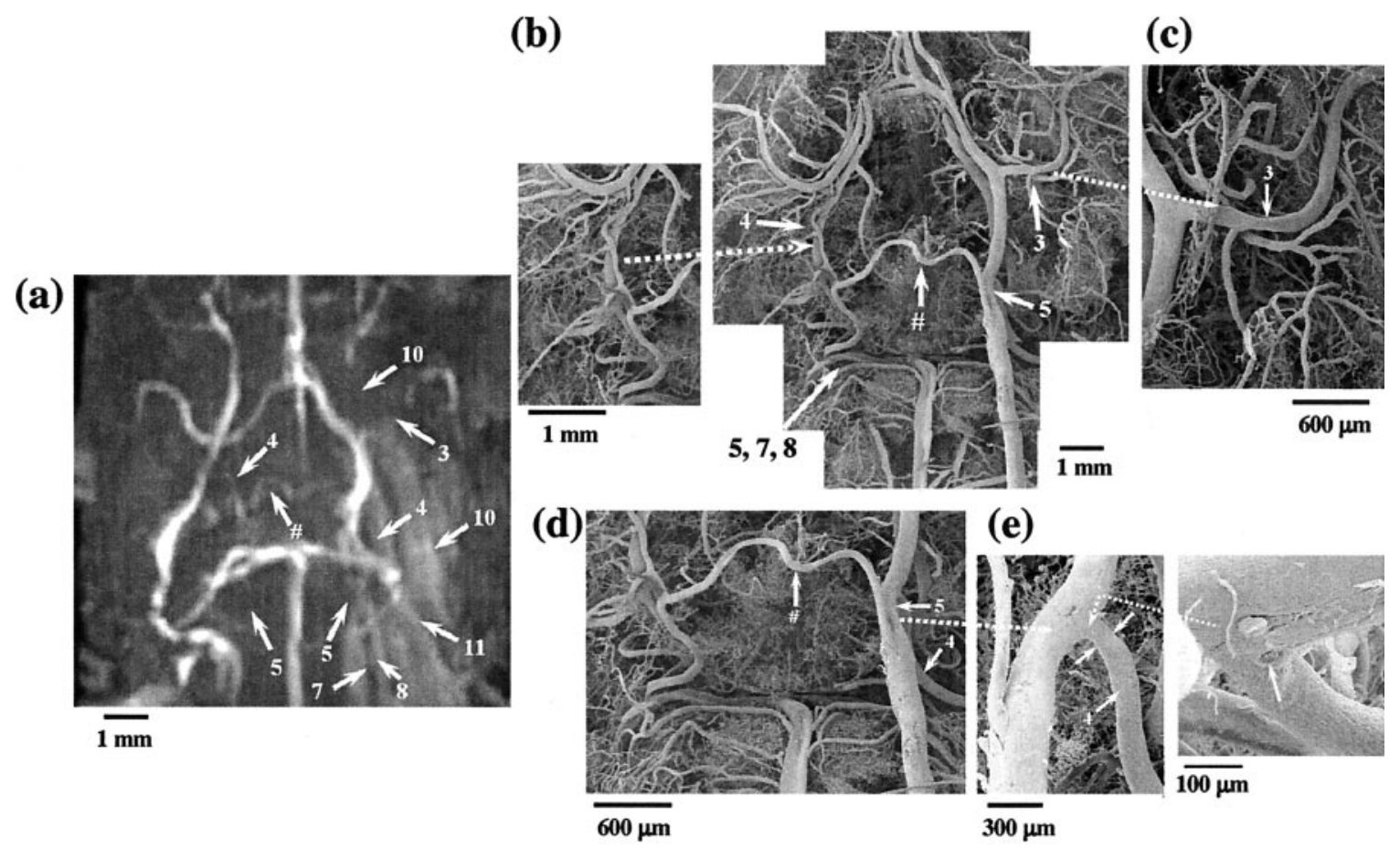

Figure 5. Twenty-month-old APP23 mouse. $a$, The arrows in the angiogram indicate flow voids at the level of the middle cerebral artery (3), the posterior cerebral arteries (4), the carotid arteries $(5,7,8)$, and the pterygopalatine $(10,11) \cdot b$, Corresponding corrosion cast demonstrating vessel elimination at the level of the posterior cerebral artery $(4)$ and the carotid arteries $(5,7,8)$ on the left side of the circle of Willis. $c, d$, Details of the cast presented in $b$ showing constrictions at the level of the right middle cerebral (3) and the internal carotid (5) arteries, respectively. $e$, A constriction (left, opposed arrows) and an inclusion of unknown kind (right, arrow) were detected at the level of the right posterior cerebral artery (4). The picture on the right was taken from the internal side of the circle of Willis. Vessel constrictions and inclusions could be the cause of turbulence resulting in flow voids depicted by the MR angiograms.
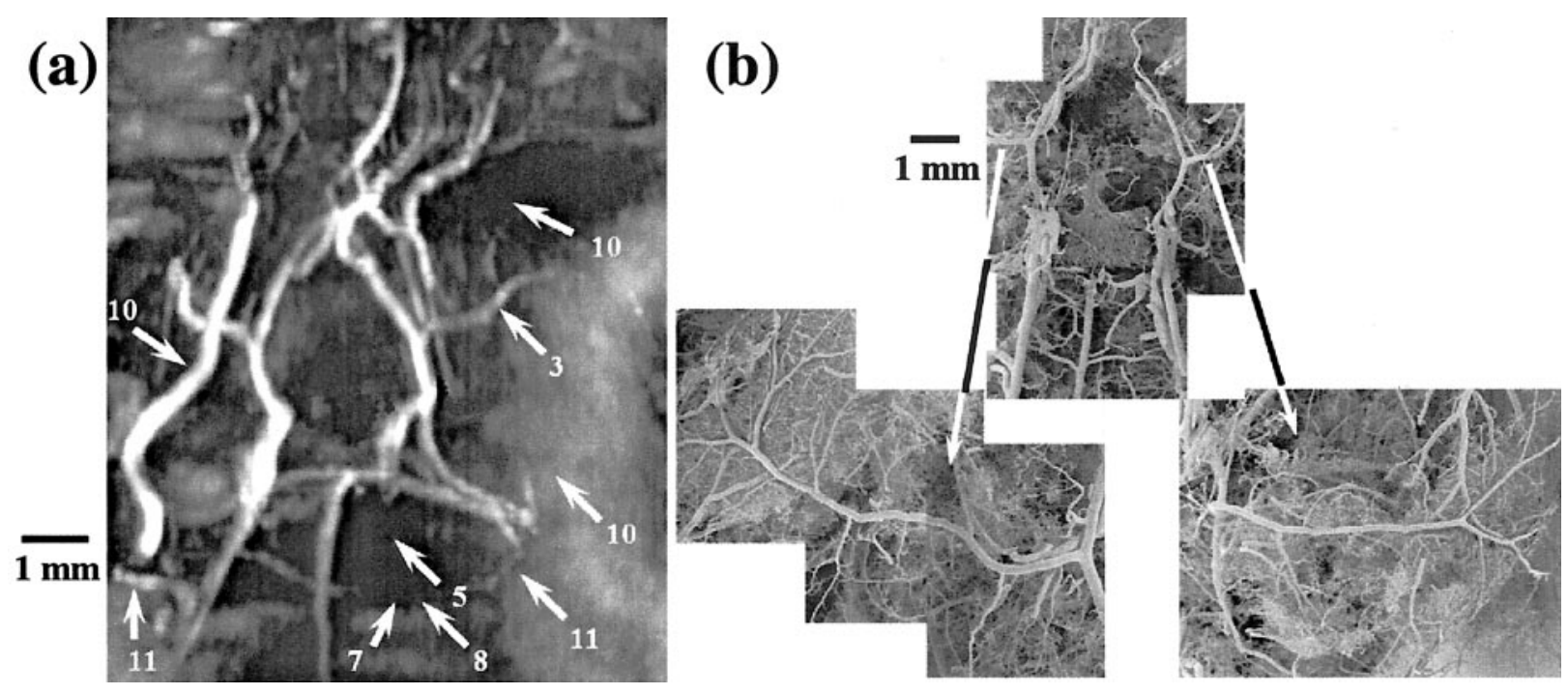

Figure 6. Twenty-month-old APP23 mouse. a, Angiogram showing perturbed flow at the level of the middle cerebral arteries (3), the carotid arteries $(5,7,8)$, and the pterygopalatine $(10,11)$. $b$, Corrosion cast demonstrating the different diameters of the middle cerebral arteries.

(e.g., posterior communicating arteries), which can lead to endothelial cell death. There is mounting evidence suggesting that soluble, oligomeric $A \beta$ assemblies cause substantial neuronal dysfunction before the appearance of amyloid deposits (Klein et al., 2001; Walsh et al., 2002). Amyloid fibril formation and deposition thus may be later stages of a process in which pathogenic events already occur early and are mediated by oligomeric assemblies (Kirkitadze et al., 2002; Selkoe, 2002). In APP23 transgenic mice, CAA is not formed by $\mathrm{A} \beta$ from vascular cells or the blood but originates from transport and drainage of neuronally pro- duced A $\beta$ (Calhoun et al., 1999; Burgermeister et al., 2000). Accordingly, it seems possible that soluble $\mathrm{A} \beta$ oligomers were drained along the large vessels of the circle of Willis, thereby causing the flow disturbances seen with MRA. Our observations are in line with reports from other transgenic mouse models of $\mathrm{AD}$ that significant neuronal injury may occur before the appearance of plaques (Hsia et al., 1999; Moechars et al., 1999; KumarSingh et al., 2000; Mucke et al., 2000).

The arterial cerebrovascular abnormalities detected by MRA and corrosion casts in the APP23 model are consistent with stud- 
ies performed on brains of AD patients at autopsy, revealing that arterioles frequently present deformations, for example, focal constrictions, kinking, twisting, and looping, as well as smooth muscle cells with an irregular shape and arrangement (Hassler, 1967; Scheibel et al., 1986; Kimura et al., 1991; Perry et al., 1998). Also, stenoses and decreased blood flow velocity were demonstrated in vivo in the middle cerebral arteries of patients with $\mathrm{AD}$ (Franceschi et al., 1995; Ishibashi et al., 1998). In these patients, there was an asymmetry in blood flow velocity, which positively correlated with the cognitive asymmetry often seen in the early phase of AD.

\section{Alternative methods to assess brain perfusion in vivo}

Another means for addressing the issue of cerebrovascular abnormalities in APP23 mice could be performing magnetic resonance imaging (MRI) perfusion measurements using, for example, an intravascular contrast agent (Rosen et al., 1991; Rudin et al., 1997) or spin-labeling techniques (Alsop et al., 2000). Such measurements, however, are only sensitive to large flow changes and would not necessarily detect more localized vascular disturbances, as was the case in this work. Laser Doppler flowmetry can also be used to monitor in vivo cerebral blood flow in the mouse brain (Niwa et al., 2002), yet this method is invasive because craniotomy needs to be performed to place the Doppler probe over a region of interest (e.g., the somatosensory cortex). Furthermore, measurements are spatially limited to the sensitive region of the probes, which typically have tip diameters smaller than $1 \mathrm{~mm}$.

The MRA procedure adopted here is noninvasive, except for the anesthesia, and angiograms were generated without the use of contrast agents. Thus, repetitive measurements performed on the same animal are limited only by anesthesia. Also, information on the arterial cerebrovascular architecture of the whole circle of Willis is obtained. Drawbacks of MRA of the mouse brain are that detected signals are restrained to main arteries and that the information on flow is only qualitative because the angiogram appearance depends not only on flow velocity. Evidently, being a method of limited sensitivity, MRA needs to be complemented by more refined techniques (e.g., corrosion cast technology), to obtain further information on the disturbed cerebrovascular architecture at the level of smaller arteries and capillaries. However, because of turbulence-induced signal attenuation in TOF MRA, changes in the vascular structure may be detected before the net flow through the vessel is affected.

In summary, using MRA, age-dependent flow voids were detected in vivo in larger arteries at the level of the circle of Willis in old but not in young APP23 transgenic mice. Corrosion cast technology revealed that, at the sites where flow voids were detected in vivo, vessel elimination, deformation, or both had taken place. In addition, casts assisted the identification of smaller vessels, most likely newly formed as substitution or anastomosis within the circle of Willis. Because no deposits of aggregated $\mathrm{A} \beta$ were observed in large arteries in the region of the circle of Willis, the present results suggest that soluble $\mathrm{A} \beta$ may exert deleterious effects on the vasculature. The loss of vascular integrity described here might provide the basis for the age-related impairment of the cerebral blood volume response to pharmacological stimulation shown recently in brain functional MRI studies in APP23 mice (Mueggler et al., 2002). The present results thus support the idea that cerebral microcirculatory abnormalities evolving progressively could contribute to $\mathrm{AD}$ pathogenesis and the cognitive impairment.

\section{References}

Alsop DC, Detre JA, Grossman M (2000) Assessment of cerebral blood flow in Alzheimer's disease by spin-labeled magnetic resonance imaging. Ann Neurol 47:93-100.

Andersen JK (2001) Genetically engineered mice and their use in aging research. Mol Biotechnol 19:45-57.

Arendash GW, Su GC, Crawford FC, Bjugstad KB, Mullan M (1999) Intravascular beta-amyloid infusion increases blood pressure: implications for a vasoactive role of beta-amyloid in the pathogenesis of Alzheimer's disease. Neurosci Lett 268:17-20.

Beckmann N (2000) High resolution magnetic resonance angiography noninvasively reveals mouse strain differences in the cerebrovascular anatomy in vivo. Magn Reson Med 44:252-258.

Beckmann N, Stirnimann R, Bochelen D (1999) High resolution magnetic resonance angiography of the mouse brain: application to murine focal cerebral ischemia models. J Magn Reson 140:442-450.

Bornemann KD, Staufenbiel M (2000) Transgenic mouse models of Alzheimer's disease. Ann NY Acad Sci 908:260-266.

Burgermeister P, Calhoun ME, Winkler DT, Jucker M (2000) Mechanisms of cerebrovascular amyloid deposition: lesson from mouse models. Ann NY Acad Sci 903:307-316.

Calhoun ME, Burgermeister P, Phinney AL, Stalder M, Tolnay M, Wiederhold KH, Abramowski D, Sturchler-Pierrat C, Sommer B, Staufenbiel M, Jucker M (1999) Neuronal overexpression of mutant amyloid precursor protein results in prominent deposition of cerebrovascular amyloid. Proc Natl Acad Sci USA 96:14088-14093.

De la Torre JC, Mussivand T (1993) Can disturbed brain microcirculation cause Alzheimer's disease? Neurol Res 15:146-153.

Duff K, Rao MV (2001) Progress in the modeling of neurodegenerative diseases in transgenic mice. Curr Opin Neurol 14:441-447.

Franceschi M, Alberoni M, Bressi S, Canal N, Comi G, Fazio F, Grassi F, Perani D, Volonte MA (1995) Correlations between cognitive impairment, middle cerebral artery flow velocity and cortical glucose metabolism in the early phase of Alzheimer's disease. Dementia 6:32-38.

Gilbert JJ, Vinters HV (1983) Cerebral amyloid angiopathy: incidence and complications in the aging brain. I. Cerebral hemorrhage. Stroke 14:915-923.

Grammas P (2000) A damaged microcirculation contributes to neuronal cell death in Alzheimer's disease. Neurobiol Aging 21:199-205.

Hardy JA, Higgins GA (1992) Alzheimer's disease: the amyloid cascade hypothesis. Science 256:184-185.

Hassler O (1967) (1967) Arterial deformities in senile brains: the occurrence of the deformities in a large autopsy series and some aspects of their functional significance. Acta Neuropathol (Berl) 8:219-229.

Hock Jr BJ, Lamb BT (2001) Transgenic mouse models of Alzheimer's disease. Trends Genet 17:S7-S12.

Hsia AY, Masliah E, McConlogue L, Yu GQ, Tatsuno G, Hu K, Kholodenko D, Malenka RC, Nicoll RA, Mucke L (1999) (1999) Plaqueindependent disruption of neural circuits in Alzheimer's disease mouse models. Proc Natl Acad Sci USA 96:3228-3233.

Ishibashi K, Tanaka K, Nakabayashi T, Nakamura M, Uchiyama M, Okawa M (1998) Latent cerebral artery stenoses on magnetic resonance angiography in a patient diagnosed as probable Alzheimer disease. Psychiatry Clin Neurosci 52:93-96.

Kimura T, Hashimura T, Miyakawa T (1991) (1991) Observations of microvessels in the brain with Alzheimer's disease by the scanning electron microscopy. Jpn J Psychiatry Neurol 45:671-676.

Kirkitadze MD, Bitan G, Teplow DB (2002) Paradigm shifts in Alzheimer's disease and other neurodegenerative disorders: the emerging role of oligomeric assemblies. J Neurosci Res 69:567-577.

Klein WL, Krafft GA, Finch CE (2001) Targeting small A $\beta$ oligomers: the solution to an Alzheimer's disease conundrum? Trends Neurosci 24:219-224.

Kumar-Singh S, Dewachter I, Moechars D, Lubke U, De Jonghe C, Ceuterick C, Checler F, Naidu A, Cordell B, Cras P, Van Broeckhoven C, Van Leuven F (2000) Behavioral disturbances without amyloid deposits in mice overexpressing human amyloid precursor protein with Flemish (A692G) or Dutch (E693Q) mutation. Neurobiol Dis 7:9-22.

Meyer EP (1989) Corrosion casts as a method for investigation of the insect tracheal system. Cell Tissue Res 256:1-6.

Meyer EP, Allison DW, Campbell IL, Siggins GR, Krucker T (2000) The microvasculature of transgenic mice with glial expression of interleukin 6 
shows extensive morphological changes as revealed by vascular corrosion casts. Soc Neurosci Abstr 26:64.

Moechars D, Dewachter I, Lorent K, Reverse D, Baekelandt V, Naidu A, Tesseur I, Spittaels K, Van Den Haute C, Checler F, Godaux E, Cordell B, Van Leuven F (1999) Early phenotypic changes in transgenic mice that overexpress different mutants of amyloid precursor protein in brain. J Biol Chem 274:6483-6492.

Mucke L, Masliah E, Yu GQ, Mallory M, Rockenstein EM, Tatsuno G, Hu K, Kholodenko D, Johnson-Wood K, McConlogue L (2000) High-level neuronal expression of $\mathrm{A} \beta(1-42)$ in wild-type human amyloid protein precursor transgenic mice: synaptotoxicity without plaque formation. J Neurosci 20:4050-4058.

Mueggler T, Sturchler-Pierrat C, Baumann D, Rausch M, Staufenbiel M, Rudin M (2002) Compromised hemodynamic response in amyloid precursor protein transgenic mice. J Neurosci 22:7218-7224.

Niwa K, Porter VA, Kazama K, Cornfield D, Carlson GA, Iadecola C (2001) Abeta-peptides enhance vasoconstriction in cerebral circulation. Am J Physiol 281:H2417-H2424.

Niwa K, Kazama K, Younkin L, Younkin SG, Carlson GA, Iadecola C (2002) Cerebrovascular autoregulation is profoundly impaired in mice overexpressing amyloid precursor protein. Am J Physiol 283:H315-H323.

Perry G, Smith MA, McCann CE, Siedlak SL, Jones PK, Friedland RP (1998) Cerebrovascular muscle atrophy is a feature of Alzheimer's disease. Brain Res 791:63-66.

Price JM, Sutton ET, Hellermann A, Thomas T (1997) Beta-amyloid induces cerebrovascular endothelial dysfunction in the rat brain. Neurol Res 19:534-538.

Probst A, Langui D, Ulrich J (1991) Alzheimer's disease: a description of the structural lesions. Brain Pathol 1:229-239.

Reese T, Bochelen D, Sauter A, Beckmann N, Rudin M (1999) Magnetic resonance angiography of the rat cerebrovascular system without the use of contrast agents. NMR Biomed 12:189-196.

Rosen BR, Belliveau JW, Aronen HJ, Kennedy D, Buchbinder BR, Fischman A, Gruber M, Glas J, Weisskoff RM, Cohen MS, Hochberg FH, Brady TJ (1991) Susceptibility contrast imaging of cerebral blood volume: human experience. Magn Reson Med 22:293-299.

Rudin M, Beckmann N, Sauter A (1997) Analysis of tracer transit time in rat brain after carotid artery and femoral vein administrations using linear system theory. Magn Reson Imaging 15:551-558.
Scheibel AB, Duong T, Tmiyasu U (1986) The biological substrates of Alzheimer's disease. New York: Academic.

Selkoe DJ (2002) Alzheimer's disease is a synaptic failure. Science 298:789-791.

Snowdon DA, Greiner LH, Mortimer JA, Riley KP, Greiner PA, Markesbery WR (1997) Brain infarction and the clinical expression of Alzheimer disease: the Nun Study. JAMA 277:813-817.

Sparks DL (1997) Coronary artery disease, hypertension, ApoE, and cholesterol: a link to Alzheimer's disease? Ann NY Acad Sci 826:128-146.

Staufenbiel M, Sommer B (1998) Transgenic animal models in the development of therapeutic strategies for Alzheimer's disease. In: Molecular biology of Alzheimer's disease: genes and mechanisms involved in amyloid generation (Haass C, ed), pp 309-326. New York: Harwood.

Sturchler-Pierrat C, Staufenbiel M (2000) Pathogenic mechanisms of Alzheimer's disease analyzed in the APP23 transgenic mouse model. Ann NY Acad Sci 920:134-139.

Sturchler-Pierrat C, Abramowski D, Duke M, Wiederhold KH, Mistl C, Rothacher S, Ledermann B, Burki K, Frey P, Paganetti PA, Waridel C, Calhoun ME, Jucker M, Probst A, Staufenbiel M, Sommer B (1997) Two amyloid precursor protein transgenic mouse models with Alzheimer disease-like pathology. Proc Natl Acad Sci USA 94:13287-13292.

Tarkowski E, Issa R, Sjogren M, Wallin A, Blennow K, Tarkowski A, Kumar P (2002) Increased intrathecal levels of the angiogenic factors VEGF and TGF-beta in Alzheimer's disease and vascular dementia. Neurobiol Aging 23:237-243.

Thomas T, Thomas G, McLendon C, Sutton T, Mullan M (1996) Betaamyloid-mediated vasoactivity and vascular endothelial damage. Nature 380:168-171.

Townsend KP, Obregon D, Quadros A, Patel N, Volmar C, Paris D, Mullan M (2002) Proinflammatory and vasoactive effects of Abeta in the cerebrovasculature. Ann NY Acad Sci 977:65-76.

Walsh DM, Klyubin I, Fadeeva JV, Cullen WK, Anwyl R, Wolfe MS, Rowan MJ, Selkoe DJ (2002) Naturally secreted oligomers of amyloid $\beta$ protein potently inhibit hippocampal long-term potentiation in vivo. Nature 416:535-539.

Winkler DT, Bondolfi L, Herzig MC, Jann L, Calhoun ME, Wiederhold KH, Tolnay M, Staufenbiel M, Jucker M (2001) Spontaneous hemorrhagic stroke in a mouse model of cerebral amyloid angiopathy. J Neurosci 21: $1619-1627$. 